\title{
Effects of Ground-Based Skidding on Soil Physical Properties in Skid Trail Switchbacks
}

\author{
Ahmad Solgi, Ramin Naghdi, Eric K. Zenner, Petros A. Tsioras, Vahid Hemmati
}

\begin{abstract}
Effective skid-trail design requires a solid understanding of vehicle-soil interactions, yet virtually no data exist on the effects of harvest traffic on soils in the switchback curves common in mountainous terrain. We contrast for the first time the effect of skidding on dry bulk density, total porosity, macroporosity, and microporosity in the straight segments of the skid trail and in various positions within switchbacks of differing trail curvature (deflection angle) on different slope gradients. Treatment plots with three replications included combinations of two classes of curvature (narrow $=$ high deflection angle, $60-70^{\circ}$; wide $=$ low deflection angle, $110-130^{\circ}$ ) and two categories of slope gradient (gentle $=\leq 20 \%$; steep $=>20 \%$ ). The Cambisol soil was sampled in control and trafficked areas both before and after three passes with a rubbertired skidder. After only three passes, significant effects were seen for dry soil bulk density (+), total porosity (-), macroporosity (-), and microporosity (+), with steady trends from undisturbed controls to straight segments to wide curves to narrow curves. Soil damage increased gradually and consistently toward the apex of the curve, particularly in narrow curves on gentle slopes. Our results establish that curvature and switchback position are important factors affecting soil compaction in ground skidding. The strong observed effects of even low harvest traffic volume on soil physical properties in curves indicate that the degree of soil compaction in skid trails may be underestimated in areas with numerous switchbacks, the placement of which within a skid trail system may require careful consideration on mountainous terrain.
\end{abstract}

Keywords: Curve radius, deflection angle, soil compaction, skid trail gradient

\section{Introduction}

Compaction of forest soils is a major problem in ground-based timber harvesting with heavy machinery that can change the physical and chemical properties of the soil, soil fauna, and plant diversity (Farrakh Nawaz et al. 2013) and result in extensive damage that can persist for many years (McColl 1995). Compaction involves the rearrangement and closer packing of the solid soil particles, which results in adverse soil changes such as increased bulk density (Hatchell et al. 1970, Froehlich et al. 1981), reduced total porosity (Rab 1994, Najafi et al. 2009, Ezzati et al. 2011, Solgi et al. 2013), reduced soil permeability, infiltration capacity, and water movement (Froehlich et al. 1981, Murray and Buttle 2004, Ezzati et al. 2012), and increased surface runoff and erosion (Greacen and Sands 1980, Safari et al. 2016). Compaction that reduces air-filled macroporosity to below $10 \%$ of the total soil volume can restrict air diffusion and severely limit microbial activity, root proliferation, and plant growth (Greacen and Sands 1980, Brady and Weil 2002, Ampoorter et al. 2007). Ultimately, soil compaction can reduce tree height, diameter, and volume growth (Williamson and Neilsen 2003, Murphy et al. 2004, Tan et al. 2006).

The damage caused by harvesting equipment is related to three major compacting forces exerted on soils:

$\Rightarrow$ a vertical force due to dynamic load of wheels

$\Rightarrow$ shear stress caused by slippage of wheels

$\Rightarrow$ vibration of engines through tires (Koslowski 1999, Vossbrink and Horn 2004, Yavuzcan et al. 2005).

Although the effect of these forces strongly depends on the number of equipment passes, various other factors further modify the extent and severity of soil compaction, including inherent soil properties such as soil texture, soil structure, soil organic matter, 
soil moisture content, and pore size distribution, and the amount and type of machine pressure and vibration applied, wheel slip, tree size and suspension, skid trail conditions, and skid trail slope (Hatchell et al. 1970, Ampoorter et al. 2007, Zenner et al. 2007, Jamshidi et al. 2008, Naghdi and Solgi 2014, Solgi and Najafi 2014, Hosseini et al. 2015). An understanding of vehicle-soil interactions (Cambi et al. 2015) permits the development of optimal skid trail networks to minimize the adverse effects of ground-based harvesting traffic (cf. Dey 1994, Grigal 2000).

In mountainous forests with their inherently uneven topography, however, it is often difficult to maintain the recommended grades (Dykstra and Heinrich 1996, Najafi et al. 2009). Here, skid trails may traverse steep portions of slopes only by installing frequent switchback curves (Cavalli and Grigolato 2010). However, whereas vehicle-soil interactions are tolerably well understood on straight skid trails (e.g., Jamshidi et al. 2008, Najafi et al. 2009, Solgi et al. 2013, Solgi and Najafi 2014, Solgi et al. 2016), our understanding of the effects of ground-based harvesting traffic on soil physical properties in skid trail switchbacks is still very limited. Despite the prevalence on mountainous terrain of skid trail curves, where vertical forces, sheer stress, and engine vibration are likely to be greatest, the effects of skidding in switchbacks is virtually undocumented (but see Thawornwong 1996). For example, in a recent detailed review of machinery-induced effects on forests soils, there was no coverage of switchbacks at all (Cambi et al. 2015).

The aim of this study was thus to investigate whether skidding would result in more adverse soil physical properties (dry bulk density, total porosity, macroporosity, and microporosity) in switchbacks compared to straight skid trail segments. Specifically, we hypothesized that physical soil properties following skidding would:

$\Rightarrow$ differ between switchbacks and straight segments of the skid trail

$\Rightarrow$ depend on the degree of curvature of the switchback

$\Rightarrow$ vary with position within the switchback

$\Rightarrow$ depend on the slope gradient.

\section{Material and methods}

\subsection{Site Description}

The study was conducted during August-September 2014 in compartment 41 of the third district in Shenrood forest, Guilan Province, northern Iran $\left(36^{\circ} 31^{\prime} 56^{\prime \prime} \mathrm{N}\right.$ to $36^{\circ} 32^{\prime} 11^{\prime \prime} \mathrm{N}$ latitude and $51^{\circ} 47^{\prime} 49^{\prime \prime} \mathrm{E}$ to $51^{\circ} 47^{\prime} 56^{\prime \prime}$ E longitude). The forest is dominated by oriental beech (Fagus orientalis Lipsky) with an average canopy cover of $80 \%$, stand density of 170 trees ha-1, mean tree diameter of $29.7 \mathrm{~cm}$, and mean tree height of $22.9 \mathrm{~m}$. The soil class is a Cambisol (World Reference Base (WRB), FAO 2015) and soil texture is a clayloam. The study area is located at an elevation of approximately $800 \mathrm{~m}$ above sea level with a northerly aspect. The average annual rainfall recorded at the closest national weather station about $20 \mathrm{~km}$ from the research site is $860 \mathrm{~mm}$. The maximum mean monthly rainfall of $120 \mathrm{~mm}$ usually occurs in October, while the minimum rainfall of $25 \mathrm{~mm}$ occurs in August. The mean annual temperature is $15^{\circ} \mathrm{C}$, with lowest temperatures in February. The average depth of soil to the bedrock is $70 \mathrm{~cm}$. At the time of skidding, the weather was dry and warm; the average water content of the soil was $210 \mathrm{~g} \mathrm{~kg}^{-1}(21 \%)$. The soil had not been driven on before the experiment.

At the study site, a combination of group selection and single-tree selection silvicultural treatments was applied. In Hyrcanian forests, harvesting and silviculture operations are most common in autumn and winter, while extraction of logs is usually completed in spring and summer. Harvesting and processing are typically performed by hand-felling using chainsaws. Highly mechanized systems, such as harvesters and feller-bunchers, are not used because most of the mature hardwood forests are located on mountainous sites with steep slopes or in lowlands on clay soils sensitive to machine disturbance. Instead, transportation of logs from forest stand to roadside is generally done with cable skidders such as the rubber-tired $\gg$ Timberjack 450C « skidder (no chains or tracks were installed on the skidder during skidding) with tire size of $775 \times 813 \mathrm{~mm}$, a weight of $10,257 \mathrm{~kg}$, engine power of $132 \mathrm{~kW}$, and a specific ground pressure of $221 \mathrm{kPa}$.

\subsection{Experimental Design and Data Collection}

For this study, a skid trail containing multiple switchbacks, of varying curvature, that encompassed a range of longitudinal slope steepness but no lateral slope was delineated. A $2 \times 2$ factorial experimental design ( 2 slope classes $\times 2$ curvature classes) with three replicates each of the four treatment combinations was used, resulting in a total of 12 experimental units (switchbacks). Based on the longitudinal profile of the skid trail, trail segments that ranged between $4-12 \%$ in slope were classified as gentle $(\leq 20 \%)$ and those between $24-28 \%$ as steep ( $>20 \%$ ) (cf. Najafi et al. 2010). For each slope class, two curvature classes were established: curves with a high deflection angle of $60-70^{\circ}$ (narrow) and curves with a low deflection angle of $110-130^{\circ}$ (wide). The deflection angle of a curve was measured from a single measuring location positioned 


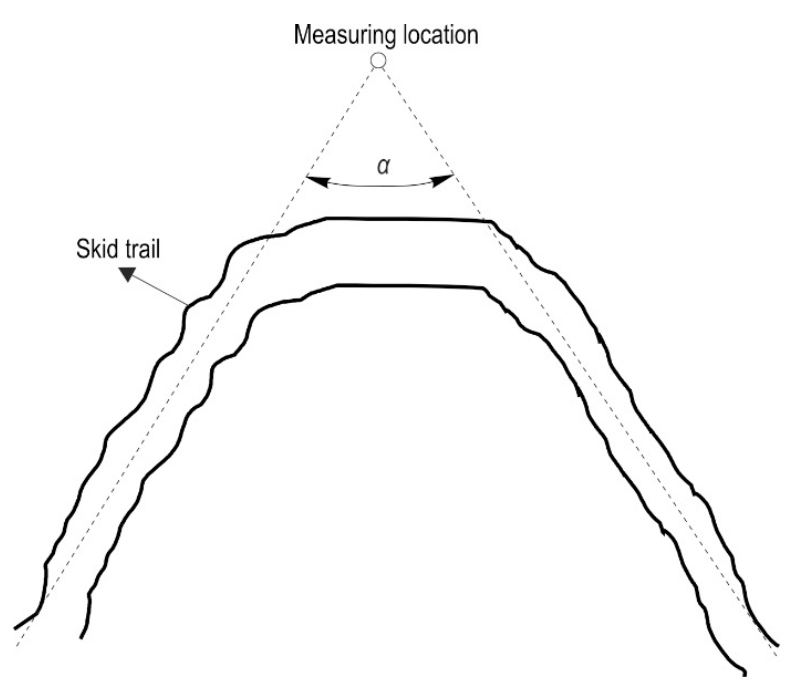

Fig. 1 Sketch of the skid trail layout showing the measuring location from which the deflection angle $(\alpha)$ was measured. Narrower curves have a deflection angle $\alpha=60-70^{\circ}$ whereas wider curves have a deflection angle $\alpha=110-130^{\circ}$

at the point beyond the curve where the two extrapolated straight skid trail segments would have intersected (Fig. 1). The deflection angle was determined by measuring the azimuths of the two lines with a compass and computing the differences between the two azimuths.

At each experimental unit, 9 plots $(2 \mathrm{~m}$ long $\times 4 \mathrm{~m}$ wide) were established at different positions in or near the switchback and soil samples were collected both prior to skidding and after three passes with an unloaded skidder (Fig. 2). Four switchback positions were sampled: one plot was established in the middle (apex) of each curve (central plot, $\mathrm{CP}$ ), one each $3 \mathrm{~m}$ away on either side of the $\mathrm{CP}$ (first plots, FP), one each $3 \mathrm{~m}$ further out from the FP (second plots, SP), and one each $15 \mathrm{~m}$ further out from the SP (third plots, TP). In addition, two plots were placed on straight segments of the skid trail on either side of the switchback, 30-50 $\mathrm{m}$ away from the SP.

Within each $2 \mathrm{~m}$ long plot, soil samples were collected in three locations along each of two randomly placed (but $\geq 1 \mathrm{~m}$ apart) $4 \mathrm{~m}$ wide transects that ran across the wheel track perpendicular to the direction of travel. The three soil samples on each transect were taken at $0-10 \mathrm{~cm}$ soil depth from the middle of the left wheel track, between the wheel tracks, and the middle of the right wheel track. Finally, a total of 28 soil samples were taken from undisturbed (control) locations, randomly dispersed throughout the study area but at least 50-60 m (ca. two tree lengths) perpendicular distance from the skid trail where no visual impact of skidding was observed.

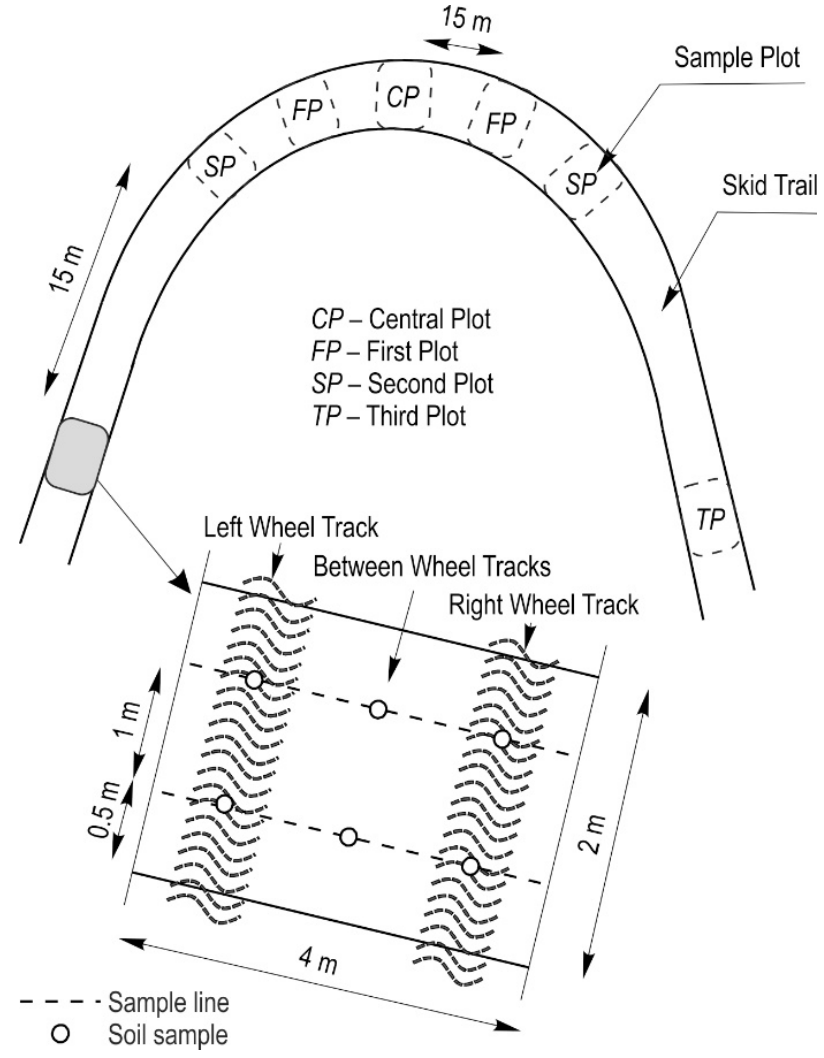

Fig. 2 Sketch of the sampling layout at each experimental unit (switchback) on the skid trail. Shown are the plots located at different positions in the switchback: central plot $(C P)$ at the apex of the curve; first plots (FP) each $3 \mathrm{~m}$ on either side of the $C P$; second plots $(S P)$ each $3 \mathrm{~m}$ further out from the FP; third plots $(T P)$ each $15 \mathrm{~m}$ further out from the SP. The full design included 2 additional plots on straight segments of the trail (SST) located on additional 30-50 $\mathrm{m}$ beyond the TP (not shown). Within each plot, three soil samples each were taken from a depth of 0-10 cm along two parallel transects, including within the left and right wheel tracks and between the tracks

Soil samples were collected with a soil hammer and rings (diameter $5 \mathrm{~cm}$, length $10 \mathrm{~cm}$ ) and immediately put in polyethylene bags and labeled. Samples were brought to the laboratory and promptly weighed before the water content was quantified gravimetrically by oven drying the samples at $105^{\circ} \mathrm{C}$ for $24 \mathrm{~h}$ (Kalra and Maynard 1991).

Dry soil bulk density $\left(D_{\mathrm{b}}, \mathrm{g} \mathrm{cm}^{-3}\right)$ was calculated as Eq. (1):

$$
D_{b}=\frac{W_{d}}{V C}
$$

Where:

$W_{\mathrm{d}}$ is the weight of dry soil, $\mathrm{g}$

VC is the volume of soil cores, $196.25 \mathrm{~cm}^{3}$. 
Total soil porosity $\left(T P, \mathrm{~m}^{3} \mathrm{~m}^{-3}\right)$ was calculated as Eq. (2):

$$
T P=\left(1-\frac{D_{b}}{2.65}\right)
$$

Where:

$2.65, \mathrm{~g} \mathrm{~cm}^{-3}$ is the soil particle density (Freeze and Cherry 1979) (3):

Microporosity $\left(M I P, \mathrm{~m}^{3} \mathrm{~m}^{-3}\right)$ was calculated as Eq.

$$
M I P=\theta_{m} \times D_{b}
$$

Where:

$\theta_{\mathrm{m}} \quad$ water content on a mass basis, \% (Solgi et al. 2016). (4):

Macroporosity $\left(M P, \mathrm{~m}^{3} \mathrm{~m}^{-3}\right)$ was calculated as Eq.

$$
M P=T P-M I P
$$

\subsection{Statistical Analysis}

Samples were averaged to the plot-level for analysis (i.e. across transect locations). Two-way ANOVA was used to assess the significance of differences in $D_{\mathrm{b}}, T P$, $M P$, and $M I P$ between different slope classes, curvature classes, and their interaction. Tukey's HSD test was used to determine which combinations of slope and curvature differed statistically significantly from each other and from straight skid trail segments and controls, at an overall $\alpha$-level of 0.05 . For each slope class $\times$ curvature class combination, Tukey's HSD was also used to determine whether $D_{\mathrm{b}}, T P, M P$, and MIP differed by position within the switchback. The SPSS software version 11.5 was used for all statistical analyses.

\section{Results}

Average values of all four soil physical properties differed significantly between switchbacks and straight segments of the skid trail and depended strongly on the degree of curvature (Table 1). Averages of $D_{\mathrm{b}}, T P, M P$, but not $M I P$, also depended on the slope gradient of the skid trail and, in the case of $D_{\mathrm{b}}$ and $M P$, on the interaction of slope class $\times$ curvature class (Table 1$)$. On average, $D_{\mathrm{b}}\left(1.21 \mathrm{~g} \mathrm{~cm}^{-3}\right)$ was greatest, while TP $\left(0.55 \mathrm{~m}^{3} \mathrm{~m}^{-3}\right)$ and $M P\left(0.21 \mathrm{~m}^{3} \mathrm{~m}^{-3}\right)$ were least, in narrow curves on steep terrain, whereas $D_{\mathrm{b}}$ $\left(0.94 \mathrm{~g} \mathrm{~cm}^{-3}\right)$ was least, and TP $\left(0.64 \mathrm{~m}^{3} \mathrm{~m}^{-3}\right)$ and $M P$ $\left(0.34 \mathrm{~m}^{3} \mathrm{~m}^{-3}\right)$ greatest, in wide curves on gentle terrain.

Skidding increased average $D_{\mathrm{b}}$ by $14-57 \%$ on straight skid trail segments, $14-86 \%$ in wide curves,
Table 1 Analysis of variance ( $p$ values) of the effects of switchback curvature, slope gradient, and their interaction on the soil physical attributes dry bulk density, total porosity, macroporosity, and microporosity on a skid trail after three passes with a Timberjack $450 \mathrm{C}$ skidder

\begin{tabular}{|l|c|c|c|c|}
\hline Source variable & $\begin{array}{c}\text { Dry bulk } \\
\text { density }\end{array}$ & $\begin{array}{c}\text { Total } \\
\text { porosity }\end{array}$ & $\begin{array}{c}\text { Macropo- } \\
\text { rosity }\end{array}$ & $\begin{array}{c}\text { Micropo- } \\
\text { rosity }\end{array}$ \\
\hline Slope class & $\leq 0.01$ & $\leq 0.01$ & $\leq 0.01$ & 0.115 \\
\hline Curvature class & $\leq 0.01$ & $\leq 0.01$ & $\leq 0.01$ & $\leq 0.01$ \\
\hline Slope $\times$ Curvature & $\leq 0.01$ & 0.815 & $\leq 0.01$ & 0.613 \\
\hline
\end{tabular}

${ }^{*} p$ values less than 0.05 are given in bold

and $29-100 \%$ in narrow curves compared to undisturbed controls (Table 2). Skidding decreased average TP by $8-25 \%$ on straight trail segments, $9-32 \%$ in wide curves, and $12-36 \%$ in narrow curves compared to undisturbed controls. Similarly, skidding decreased average $M P$ by $23-50 \%$ on straight trail segments, $23-71 \%$ in wide curves, and $27-81 \%$ in narrow curves compared to undisturbed controls. In contrast, skidding increased average MIP by $21-38 \%$ on straight trail segments, $17-54 \%$ in wide curves, and $21-58 \%$ in narrow curves compared to undisturbed controls.

Regardless of curvature class, the effects of skidding on soil physical properties differed strongly and significantly by position within the switchback, with the greatest effects at the apex of the curve (Table 2). A maximum in $D_{\mathrm{b}}$ and $M I P$, and a minimum in $T P$ and $M P$, was observed in the $C P$, with decreasing effects of skidding the further the plots were positioned from the apex of the curve. In most cases, a significant difference in responses was already seen between the $C P$ and $F P$, and in all cases between the $C P$ and $S P$ and TP. However, even the $S P$ and $T P$ were significantly different for all four soil properties in narrow curves on gentle slopes. In general, differences in average soil physical properties among positions along the switchback were more pronounced on gentle than steep slopes.

Regardless of switchback position or curvature class, $D_{\mathrm{b}}$ was consistently greater, and TP and MP consistently lower, on steeper than gentle slopes; MIP did not differ consistently by slope class. Whereas $D_{\mathrm{b}}$ was significantly lower, and TP and $M P$ significantly greater, in wide compared to narrow curves at every position on slopes $\leq 20 \%, D_{\mathrm{b}}, T P$, and $M P$ did not differ significantly between narrow and wide curves at any position on slopes $>20 \%$ (Table 2). MIP was not consistently lower in wide compared to narrow curves, however. $\mathrm{Db}$ and MIP were consistently lower, and TP and 
Table 2 Average soil properties of a Cambisol in an undisturbed control area (UN) and following three passes of a Timberjack 450C skidder on a skid trail on two slope gradients $(\leq 20 \%$ and $>20 \%$ longitudinal profile of the skid trail) and two curvature classes (high deflection angle of $60-70^{\circ}=$ narrow curves and low deflection angle of $110-130^{\circ}=$ wide curves) at various positions: the central plot $(C P)$ at the apex of the curve; first plots (FP) each $3 \mathrm{~m}$ on either side of the $C P$; second plots $(S P)$ each $3 \mathrm{~m}$ further out from the FP; third plots (TP) each $15 \mathrm{~m}$ further out from the SP; and straight segments of the skid trail (SST) 30-50 m further out from the TP

\begin{tabular}{|c|c|c|c|c|c|c|c|c|c|c|}
\hline \multirow{2}{*}{ Slope Class } & \multirow{2}{*}{ Curvature Class } & \multicolumn{9}{|c|}{ Position } \\
\hline & & $T P$ & $S P$ & $F P$ & $C P$ & $F P$ & $S P$ & $T P$ & SST & UN \\
\hline \multicolumn{11}{|c|}{ Soil bulk density $\left(D_{\mathrm{b}}\right), \mathrm{g} \mathrm{cm}^{-3}$} \\
\hline$\leq 20 \%$ & Narrow & $0.9^{d}$ & $1.0^{c}$ & $1.2^{\mathrm{b}}$ & $1.4^{\mathrm{a}}$ & $1.2^{b}$ & $1.1^{\mathrm{c}}$ & $1.0^{\mathrm{d}}$ & $0.9^{d}$ & $0.7^{\mathrm{e}}$ \\
\hline$\leq 20 \%$ & Wide & $0.8^{c}$ & $0.9^{\mathrm{bc}}$ & $1.0^{\mathrm{b}}$ & $1.1^{\mathrm{a}}$ & $1.0^{\mathrm{b}}$ & $0.9^{\mathrm{bc}}$ & $0.9^{c}$ & $0.8^{c}$ & $0.7^{\mathrm{d}}$ \\
\hline$>20 \%$ & Narrow & $1.1^{\mathrm{c}}$ & $1.2^{\mathrm{bc}}$ & $1.2^{b}$ & $1.4^{\mathrm{a}}$ & $1.2^{b}$ & $1.2^{\mathrm{bc}}$ & $1.2^{c}$ & $1.1^{c}$ & $0.7^{\mathrm{d}}$ \\
\hline$>20 \%$ & Wide & $1.1^{b}$ & $1.1^{b}$ & $1.2^{\mathrm{a}}$ & $1.3^{\mathrm{a}}$ & $1.2^{\mathrm{a}}$ & $1.2^{b}$ & $1.2^{b}$ & $1.1^{\mathrm{b}}$ & $0.7^{c}$ \\
\hline \multicolumn{11}{|c|}{ Total porosity $(T P), \mathrm{m}^{3} \mathrm{~m}^{-3}$} \\
\hline$\leq 20 \%$ & Narrow & $0.66^{d}$ & $0.61^{c}$ & $0.55^{b}$ & $0.49^{\mathrm{a}}$ & $0.55^{b}$ & $0.60^{c}$ & $0.67^{d}$ & $0.68^{d}$ & $0.76^{\mathrm{e}}$ \\
\hline$\leq 20 \%$ & Wide & $0.70^{\text {cd }}$ & $0.66^{c}$ & $0.61^{b}$ & $0.57^{\mathrm{a}}$ & $0.61^{b}$ & $0.65^{c}$ & $0.68^{b}$ & $0.70^{\text {cd }}$ & $0.76^{\mathrm{c}}$ \\
\hline$>20 \%$ & Narrow & $0.58^{\mathrm{c}}$ & $0.56^{\mathrm{bc}}$ & $0.54^{b}$ & $0.48^{\mathrm{a}}$ & $0.54^{\mathrm{b}}$ & $0.55^{\mathrm{bc}}$ & $0.57^{c}$ & $0.60^{\text {cd }}$ & $0.76^{\mathrm{d}}$ \\
\hline$>20 \%$ & Wide & $0.56^{\mathrm{bc}}$ & $0.56^{b}$ & $0.54^{\mathrm{a}}$ & $0.52^{\mathrm{a}}$ & $0.54^{\mathrm{a}}$ & $0.56^{b}$ & $0.57^{\mathrm{bc}}$ & $0.57^{\mathrm{bc}}$ & $0.76^{\circ}$ \\
\hline \multicolumn{11}{|c|}{ Macroporosity $(M P), \mathrm{m}^{3} \mathrm{~m}^{-3}$} \\
\hline$\leq 20 \%$ & Narrow & $0.37^{d}$ & $0.28^{c}$ & $0.23^{b}$ & $0.10^{\mathrm{a}}$ & $0.23^{b}$ & $0.27^{c}$ & $0.38^{d}$ & $0.40^{d}$ & $0.52^{\mathrm{e}}$ \\
\hline$\leq 20 \%$ & Wide & $0.40^{c}$ & $0.36^{\mathrm{bc}}$ & $0.32^{b}$ & $0.24^{\mathrm{a}}$ & $0.28^{b}$ & $0.35^{\mathrm{bc}}$ & $0.40^{\mathrm{C}}$ & $0.40^{\mathrm{c}}$ & $0.52^{\mathrm{d}}$ \\
\hline$>20 \%$ & Narrow & $0.29^{\mathrm{c}}$ & $0.23^{\mathrm{bc}}$ & $0.19^{b}$ & $0.10^{\mathrm{a}}$ & $0.19^{b}$ & $0.23^{\mathrm{bc}}$ & $0.27^{c}$ & $0.27^{c}$ & $0.52^{\mathrm{d}}$ \\
\hline$>20 \%$ & Wide & $0.28^{c}$ & $0.29^{c}$ & $0.23^{b}$ & $0.15^{\mathrm{a}}$ & $0.22^{b}$ & $0.25^{c}$ & $0.29^{c}$ & $0.26^{c}$ & $0.52^{\circ}$ \\
\hline \multicolumn{11}{|c|}{ Microporosity $(M I P), \mathrm{m}^{3} \mathrm{~m}^{-3}$} \\
\hline$\leq 20 \%$ & Narrow & $0.29^{c}$ & $0.33^{b}$ & $0.32^{b}$ & $0.39^{\mathrm{a}}$ & $0.32^{b}$ & $0.33^{b}$ & $0.29^{c}$ & $0.29^{c}$ & $0.24^{\mathrm{d}}$ \\
\hline$\leq 20 \%$ & Wide & $0.29^{b}$ & $0.30^{\mathrm{b}}$ & $0.29^{b}$ & $0.33^{\mathrm{a}}$ & $0.32^{b}$ & $0.30^{\mathrm{b}}$ & $0.29^{b}$ & $0.30^{\mathrm{b}}$ & $0.24^{\circ}$ \\
\hline$>20 \%$ & Narrow & $0.29^{c}$ & $0.33^{\mathrm{bc}}$ & $0.35^{b}$ & $0.38^{\mathrm{a}}$ & $0.35^{b}$ & $0.32^{\mathrm{bc}}$ & $0.30^{c}$ & $0.33^{\mathrm{bc}}$ & $0.24^{\mathrm{c}}$ \\
\hline$>20 \%$ & Wide & $0.29^{\mathrm{bc}}$ & $0.28^{\mathrm{bc}}$ & $0.32^{b}$ & $0.37^{\mathrm{a}}$ & $0.32^{b}$ & $0.31^{b}$ & $0.29^{\mathrm{bc}}$ & $0.31^{b}$ & $0.24^{\circ}$ \\
\hline
\end{tabular}

Different superscript letters across a row indicate a statistical difference among positions at alpha $=0.05$

$M P$ greater, on straight skid trail segments than in skid trail curves, but these effects were not statistically significant for the third plots in narrow curves on slopes $\leq 20 \%$ or for second and third plots in all other cases.

\section{Discussion}

In this study, we are among the first to document the adverse effects of frequent switchback curves that characterize skid trails traversing steep slopes in mountainous forests with uneven topography (Cavalli and Grigolato 2010). Whereas adverse effects on soil physical properties by ground-based timber harvesting with heavy machinery has been amply documented on skid trails (e.g., Grigal 2000, Ampoorter et al. 2007), this study extends these findings showing that:

$\Rightarrow$ such adverse effects are enhanced in skid trail switchbacks compared to straight segments

$\Rightarrow$ narrower, more space-conserving switchbacks result in greater increases in soil bulk density than wider, less space-conserving switchbacks

$\Rightarrow$ these effects are most pronounced toward the apex of the switchback curve

$\Rightarrow$ the effect of harvest traffic is greatest on gentle slopes. 
As expected, increased soil bulk density (compaction) translated into reduced macroporosity and total porosity and increased microporosity, which is a commonly observed response in the pore size distribution following skidding (Greacen and Sands 1980).

In this initial investigation of the effects of harvest traffic in switchbacks, we did not formally examine the specific causes that may be responsible for more adverse soil physical conditions along the curve. Nonetheless, as increased soil bulk density from harvest traffic is primarily a function of universal physical forces (Pacejka 2012), the most plausible causes may be hypothesized for future exploration. Greater effects of skidding in switchbacks than on straight segments of the skid trail, greater effects in narrow than wider curves, and non-constant effects on soil physical properties across different positions within the switchback are largely due to:

\section{$\Rightarrow$ lateral weight/load transfer \\ $\Rightarrow$ lower speed in curves.}

Lateral weight/load transfer is the change in the distribution of the skidder weight and its load on the skidder axles and wheels that occurs when a vehicle enters a curve, which results in higher ground pressure of the wheels on the outside of the curve (and lower ground pressure of the wheels on the inside of the curve), and thus uneven soil disturbance of the wheel tracks within the skid trail (Pacejka 2012). As physical forces are particularly pronounced in narrow curves (Pacejka 2012), soils in skid trails with narrow curves are more susceptible to greater compaction than in wide curves. In addition to weight/load transfer that occurs in curves, skidders slow to enter and pass through a curve, thus spending more time in curves than on straight segments of the skid trail (Thawornwong 1996). As skidders slow to enter and pass through a curve, engine vibration increases, thus compacting the top soil more in curves than on skidder trail segments that are traversed at higher speeds (Horn et al. 1989, Solgi and Najafi 2014). The combination of greater weight/load transfer and lower machine speeds with greater vibration results in soil compaction that is particularly pronounced in narrower curves and on steeper slopes, where lower speeds are required to navigate narrower curves. Differential weight/load transfer and speed may also explain the non-constant effects on soil physical properties across different positions within the switchback, regardless of deflection angle and slope gradient. In contrast to paved highway roads that are engineered to have a more or less constant radius throughout the curve for a constant centrifugal force that enhances the safety even at higher speeds (Slimi et al. 2013), skid trails typically do not have a constant radius throughout the curve (as is often the case, including in the current study) such that the narrowest portion of the switchback typically occurs at the apex of the curve. Thus, weight/load transfer in the apex of the curve is greatest, speeds are lowest, with the result that soil compaction at this position in the curve is greatest. Finally, although soil bulk density was greater and macroporosity was smaller on steep slopes than on gentle slopes on straight segments of the skid trail, as is typically the case (e.g., Solgi and Najafi 2014), and in most switchback positions in wide curves, this was not the case at the apex of narrow curves. Greater soil loss in narrower curves on gentler slopes (Thawornwong 1996) could compensate for the soil damage incurred by increased steepness, explaining the lack of a slope effect at the apex of narrow curves, and may again reflect differential skidder speeds: due to the lower traction of machinery on steeper slopes, skidder speeds on steep slopes may already be reduced compared to more gentle slopes (Najafi et al. 2009), resulting in a larger relative reduction in speed as machinery enters a switchback on gentle slopes.

Regardless of the specific causes of soil damage in switchbacks, our results indicate that, after as few as three equipment passes, the apex of the switchback curve may be particularly vulnerable to deteriorating soil conditions following skidding, especially given that soil conditions on both slope gradients came close to the critical threshold values shown to be detrimental to future plant growth and long-term site productivity. In the central plots, particularly in narrow curves, bulk densities fell only slightly short of the critical threshold between $1.40-1.55 \mathrm{~g} \mathrm{~m}^{-3}$, above which plant roots cannot penetrate soils with light and medium texture (Kozlowski 1999). Similarly, air filled macroporosity below $10 \%$ of the total soil volume in the apex of narrow curves in both slope gradients may severely limit air diffusion, microbial activity, and root proliferation in most soils and cause site productivity to decline (Brady and Weil 2002, Ampoorter et al. 2007). Thus, on a portion of the site, a loss of future site productivity has already been achieved after only three skidder passes, which must be regarded as a low traffic volume considering that skid trails are designed to concentrate as much equipment traffic on as small an area as possible (e.g., Hatchell et al. 1970, Zenner et al. 2007). Although we did not investigate the effects of greater traffic frequencies in this study, given that the majority of adverse effects on soil physical properties typically occurs in the first three passes of a vehicle, with modest additional impact with subsequent passes (Hatchell et al. 1970, Zenner et al. 2007, Jamshidi et al. 2008), it could be expected that the observed pattern 
of effects in straight and curved segments of the skid trail would hold with greater traffic. However, further studies will be needed to assess whether the observed effects of curvature and switchback position remain constant or diminish as increasing traffic volume increases soil damage toward critical threshold values on ever larger proportions on the trail (cf. Kozlowski 1999). Either way, differential soil damage at various positions along skid trails containing switchbacks indicates that soil damage assessed on straight segments of skid trails may severely underestimate the actual soil damage in mountainous areas that include curves. Differences between straight segments and the apex of the curve of $29 \%$ for total porosity, $56 \%$ for dry bulk density, and $74 \%$ for macroporosity indicate that these differences can be sizeable, at least for some portions of the harvest area.

The results of this study reiterate recommendations for careful planning of skid trail networks that includes confining skidder traffic to as few designated skid trails as possible, maintaining slope gradients of skid trails that are as low as possible, and keeping skid trails as straight as possible. This can minimize the proportion of total stand area adversely impacted by traffic, reduce damage to the residual stand and disturbances to the forest floor, and decrease skidder travel time (e.g., Dey 1994, Grigal 2000, Zenner et al. 2007). In mountainous forests with uneven topography, where it is difficult to maintain recommended grades for skid trails of 10-20\% (Dykstra and Heinrich 1996, Najafi et al. 2009) or $\leq 30 \%$ for rubber-tired skidders on short pitches in adverse terrain (Dey 1994), installing frequent switchback curves is often unavoidable (Cavalli and Grigolato 2010). Given greater soil bulk density and reduced porosity in narrower compared to wider curves following skidder traffic, particular attention must be paid to the placement of these curves for a more optimal routing of machinery.

\section{Conclusions}

In the current study, we compared the effect of skidding on dry bulk density, total porosity, macroporosity, and microporosity in the straight segments of the skid trail and in various positions within switchbacks of differing trail curvature (deflection angle) on different slope gradients. We have concluded that adverse skidding effects on switchbacks are substantially greater than on straight segments of the skid trail. Despite the limitations of this initial study, which investigated soil physical properties on only one soil type (Cambisol) after a fixed number of passes with one particular harvesting machine, the universality of physical forces that induce soil damage on skid trails
(Pacejka 2012) suggests that some of the observed results may be broadly generalizable to other soils, forest types, climates, years, and equipment. If switchback curves are necessary to provide access to the entire cutting area, these generalizations include that:

$\Rightarrow$ soil physical properties such as bulk density and porosity can be expected to be more strongly adversely affected in the curves of the skid trail than on straight segments

$\Rightarrow$ soil damage can be expected to depend on the deflection angle of the switchback, with greater severity in narrower than in wider curves

$\Rightarrow$ the adverse effects on soil physical properties can be expected to be worse in the apex of the curve, regardless of slope gradient or curvature

$\Rightarrow$ the effects on soil physical properties of a steeper slope gradient can be expected to be more adverse in the straight segments of a skid trail and all switchback positions in wider, but not necessarily narrower, curves.

In conclusion, our results indicate that simple extrapolation of soil-machine interactions from straight segments of skid trails to the entire skid trail may not be prudent in mountainous areas, where trails include numerous switchback curves. This may particularly be the case given that only three passes of harvesting equipment (i.e., low traffic volume) were capable of inducing levels of soil damage that approached critical threshold values detrimental to plant growth and long-term site productivity in switchback curves. The subsequent implication for the layout of skid trail systems in mountainous terrains is that optimal routing of the extracting ground-based machinery may require that particular attention be paid to the placement of skid trail curves. In addition to skid trail planning, primary timber extraction planning needs to consider the type of skid trail (i.e., whether the trail is temporary or permanent), the intensity and period of logging extraction, and the size of the extracted wood to minimize adverse effects on the stand. Further research is required, however, to verify the specific causes of adverse effects of skidding in switchbacks on physical soil properties, to confirm these effects across a broader range of soil conditions, and determine how these effects are modified by increased traffic intensity.

\section{References}

Ampoorter, E., Goris, R., Cornelis, W.M., Verheyen, K., 2007: Impact of mechanized logging on compaction status of sandy forest soils. For. Ecol. Manage. 241(1-3): 162-174. https:// doi.org/10.1016/j.foreco.2007.01.019 
Brady, N.C., Weil, R.R., 2002: Elements of the nature and properties of soils. Prentice Hall, New Jersey, USA, 202-212 p.

Cambi, M., Certini, G., Neri, F., Marchi, E., 2015: The impact of heavy traffic on forest soils: a review. For. Ecol. Manage. 338: 124-138. https://doi.org/10.1016/j.foreco.2014.11.022

Cavalli, R., Grigolato, S., 2010: Influence of characteristics and extension of a forest road network on the supply cost of forest woodchips. J. For. Res. 15(3): 202-209. https://doi. org/10.1007/s10310-009-0170-4

Dey, D., 1994: Careful logging partial cutting and the protection of terrestrial and aquatic habitats. In: Rice, J.A., Logging damage: the problems and practical solutions (Ed.), Forest Research Information Paper 117, Ontario Forest Research Institute, Sault Ste. Marie, Ontario, Canada, 53-69.

Dykstra, D.P., Heinrich, R., 1996: FAO Model Code for Harvesting Practice, Food and Agriculture Organization of the United Nations, Rome, Italy.

Ezzati, S., Najafi, A., Durston, T., 2011: Impact of animal logging on soil physical properties in mule trail in Hyrcanian forests. Trans. Res. Part D: Trans. Env. 16(4): 316-320. https:// doi.org/10.1016/j.trd.2011.01.013

Ezzati, S., Najafi, A., Rab, M.A., Zenner, E.K., 2012: Recovery of soil bulk density porosity and rutting from ground skidding over a 20-year period after timber harvesting in Iran. Silva Fen. 46(4): 521-538. https://doi.org/10.14214/sf.908

Farrakh Nawaz, M., Bourrié, G., Trolard, F., 2013: Soil compaction impact and modelling. A review. Agro. Sust. Devel. 33(2): 291-309. https://doi.org/10.1007/s13593-011-0071-8

FAO, Food and Agriculture Organization of the United Nations, 2015: World reference base for soil resources 2014, International soil classification system for naming soils and creating legends for soil maps (Update 2015), World Soil Resources Reports 105, Food and Agriculture Organization of the United Nations, Rome, Italy.

Freeze, R.A., Cherry, J.A. 1979: Groundwater. Englewood Cliffs (NJ): Prentice Hall; 604 p.

Froehlich, H., Aulerich, D., Curtis, R., 1981: Designing skid trail system to reduce soil impacts from tractive logging machines. Forest Research Laboratory, Oregon State University, Research Paper 44, Corvallis Oregon, USA.

Greacen, E.L., Sands, R., 1980: Compaction of forest soils: a review. Aust. J. Soil Res. 18(2): 163-189. https://doi.org/ 10.1071/SR9800163

Grigal, D.F., 2000: Effects of extensive forest management on soil productivity. For. Ecol. Manage. 138(1-3): 169-187. https://doi.org/10.1016/S0378-1127(00)00395-9

Hatchell, G.E., Ralston, C.W., Foil, R.R., 1970: Soil Disturbances in Logging: Effects on Soil Characteristics and Growth of Loblolly Pine in the Atlantic Coastal Plain. J. For. 68(12): 772-775. https://doi.org/10.1093/jof/68.12.772

Horn, R., Blackwell, P.S., White, R., 1989: The effect of speed of wheeling on soil stresses, rut depth, and soil physical prop- erties in an ameliorated transitional red-brown earth. Soil Till. Res. 13(4): 353-364. https://doi.org/10.1016/0167-1987(89) 90043-3

Hosseini, S.A.O., Akbarimehr, M., Emadian, S.F., Agh, A., 2015: Considering the soil compaction status on logging areas in a Hyrcanian forest. J. For. Sci. 61(5): 210-215. https://doi. org/10.17221/48/2014-JFS

Jamshidi, R., Jaeger, D., Raafatnia, N., Tabari, M., 2008: Influence of two ground-based skidding systems on soil compaction under different slope and gradient conditions. Int. J. For. Eng. 19(1): 9-16. https://doi.org/10.1080/14942119.2008.10702 554

Kalra, Y.P., Maynard, D.G., 1991: Methods and manual for forest soil and plant analysis. Northern Forestry Centre NORX-319, Forestry Canada, Northwest Region, Edmonton, Alberta, Canada.

Kozlowski, T.T., 1999: Soil compaction and growth of woody plants. Scan. J. For. Res. 14(6): 596-619. https://doi. org/10.1080/02827589908540825

McColl, J.G., 1995: Forest clear-cutting soil response, in: Nierenberg W.A., Encyclopedia of Environmental Biology, Vol. 2 (Ed.), Academic Press, San Diego, California, USA, 95-103.

Murphy, M., Firth, J.G., Skinner, M.F., 2004: Long-term impacts of forest harvesting related soil disturbance on log product yields and economic potential in a New Zealand forest. Silva Fen. 38(2): 279-289. https://doi.org/10.14214/ sf.416

Murray, C.D., Buttle, J.M., 2004: Infiltration and soil water mixing on forested and harvested slopes during spring snowmelt Turkey Lakes Watershed central Ontario. J. Hydro. 306(1-4): 1-20. https://doi.org/10.1016/j.jhydrol.2004.08.032

Naghdi, R., Bagheri, I., Basiri, R., 2010: Soil disturbances due to machinery traffic on steep skid trail in the north mountainous forest of Iran. J. For. Res. 21(4): 497-502. https://doi. org/10.1007/s11676-010-0105-0

Naghdi, R., Solgi, A., 2014: Effects of skidder passes and slope on soil disturbance in two soil water contents. Cro. J. For. Eng. 35(1): 73-80.

Najafi, A., Solgi, A., Sadeghi, S.H., 2009: Soil disturbance following four wheel rubber skidder logging on the steep trail in the north mountainous forest of Iran. Soil Till. Res. 103(1): 165-169. https://doi.org/10.1016/j.still.2008.10.003

Najafi, A., Solgi, A., Sadeghi, S.H., 2010: Effects of skid trail slope and ground skidding on soil disturbance. Cas. J. Env. Sci. 8(1): 13-23.

Pacejka, H.B., 2012: Tire and vehicle dynamics, $3^{\text {rd }}$ ed., Butterworth-Heinemann, Oxford, UK.

Rab, M.A., 1994: Changes in physical properties of a soil associated with logging of Eucalyptus regnans forest in southeastern Australia. For. Ecol. Manage. 70(1-3): 215-229. https:// doi.org/10.1016/0378-1127(94)90088-4

Safari, A., Kavian, A., Parsakhoo, A., Saleh, I., Jordan, A., 2016: Impact of different parts of skid trails on runoff and soil erosion in the Hyrcanian forest (northern Iran). Geoderma. 263: 161-167. https://doi.org/10.1016/j.geoderma.2015.09.010 
Slimi, H., Ichalal, D., Arioui, H., Mammar, S., 2013: Motorcycle Maximal Safe Speed in Cornering Situation. $10^{\text {th }}$ IEEE International Conference on Networking, Sensing and Control (ICNSC2013), Apil, Evry, France, 340-346.

Solgi, A., Najafi, A., Sam Daliri, H., 2013: Assessment of Crawler Tractor Effects on Soil Surface Properties. Cas. J. Env. Sci. 11(2): 185-193.

Solgi, A., Najafi, A., 2014: The impacts of ground-based logging equipment on forest soil. J. For. Sci. 60(1): 28-34.

Solgi, A., Najafi, A., Ezzati, S., Ferencik, M., 2016: Assessment of ground-based skidding impacts on the horizontal extent and level of soil disturbance along the margin of a skid trail. An. For. Sci. 73(2): 513-522. https://doi.org/10.1007/s13595016-0544-7

Solgi, A., Naghdi, R., Labelle, E.R., Tsioras, P.A., Nikooy, M., 2016: Effect of varying machine ground pressure and traffic frequency on the physical properties of clay loam soils located in mountainous forests. Int. J. For. Eng. 27(3): 161-168. https://doi.org/10.1080/14942119.2016.1226673

Tan, X., Kabzem, R., Chang, S.X., 2006: Response of forest vegetation and foliar $\delta 13 \mathrm{C}$ and $\delta 15 \mathrm{~N}$ to soil compaction and forest floor removal in a boreal aspen forest. For. Ecol. Manage. 222(1-3): 450-458. https://doi.org/10.1016/j.foreco.2005.10.051
Thawornwong, L., 1996: The effect of skid trail curves on soil loss in a selectively harvested dipterocarp forest in East Kalimantan Indonesia, in: Putz, P.E, Elias, P., Dykstra, D.P., Heinrich, R., Research methods for reduced logging impact: workshop results (Eds.), Center for International Forestry Research (CIFOR), Jakarta, Indonesia, 19-21.

Vossbrink, J., Horn, R., 2004: Modern forestry vehicles and their impact on soil physical properties. Eur. J. For. Res. 123(4): 259-267. https://doi.org/10.1007/s10342-004-0040-8

Williamson, J.R., Neilsen, W.A., 2003: The effect of soil compaction profile disturbance and fertilizer application on the growth of eucalyptus seedlings in two glasshouse studies. Soil Till. Res. 71(2): 95-107. https://doi.org/10.1016/S01671987(03)00022-9

Yavuzcan, H.G., Matthies, D., Auernhammer, H., 2005: Vulnerability of Bavarian silty loam soil to compaction under heavy wheel traffic: impacts of tillage method and soil water content. Soil Till. Res. 84(2): 200-215. https://doi.org/10.1016/j. still.2004.11.003

Zenner, E.K., Fauskee, J.T., Berger, A.L., Puettmann, K.J., 2007: Impacts of skidding traffic intensity on soil disturbance soil recovery and aspen regeneration in north central Minnesota. North. J. Appl. For. 24(3): 177-183. https://doi. org/10.1093/njaf/24.3.177 of the Creative Commons Attribution (CC BY) license (http://creativecommons.org/licenses/by/4.0/). 
Authors' addresses:

Ahmad Solgi, $\mathrm{PhD}$ *

e-mail: solgi_ahmad231@yahoo.com

Prof. Ramin Naghdi, PhD

e-mail: rnaghdi@guilan.ac.ir

University of Guilan

Faculty of Natural Resources

Department of Forestry

Sowmeh Sara, Guilan

P.O. Box 1144

IRAN

Assoc. prof. Eric K. Zenner, PhD

e-mail: eric.zenner@psu.edu

Penn State University

Department of Ecosystem Science and Management 305 Forest Resources Building

University Park, PA 16802

USA

Petros A. Tsioras, PhD

e-mail: ptsioras@for.auth.gr

Aristotle University of Thessaloniki

Department of Forestry and Natural Environment

Laboratory of Forest Utilization POB 227

54124 Thessaloniki

GREECE

Assist. prof. Vahid Hemmati, PhD

e-mail: vahidhemmatiliau@gmail.com

Islamic Azad University

Lahijan Branch

IRAN

* Corresponding author 